\title{
Determination of the psychometric properties of the Patients' Self-Efficacy Scale in blood pressure patients
}

\author{
RAHELEH GHADIRI ${ }^{1}$, MASOUMEH ALIMOHAMMADI ${ }^{2}$, \\ HESAMEDIN ASKARI MAJDABADI ${ }^{3, *}$
}

\author{
${ }^{1}$ Semnan Health Center, Semnan University of Medical Sciences, Semnan, Iran \\ ${ }^{2}$ Psychology Unit, School of Allied Medical Sciences, Semnan University of Medical Sciences, Semnan, Iran \\ ${ }^{3}$ Nursing Care Research Center, Semnan University of Medical Sciences Semnan, Semnan, Iran \\ ${ }^{*}$ Corresponding author: Hesamedin Askari Majdabadi; Nursing Care Research Center, Semnan University of Medical Sciences Semnan, \\ 5 km road of Damghan, Educational complex, Semnan 35198 99051, Iran; Phone: +98 233335 4191; \\ Fax: +98 233335 4190; E-mail: hesamaskari@yahoo.com
}

(Received: August 21, 2017; Revised manuscript received: October 7, 2017; Accepted: January 15, 2018)

\begin{abstract}
Introduction: This study was designed to determine self-efficacy and its related factors in patients with hypertension. Materials and methods: This study is descriptive-sectional from the correlation. A total of 250 patients from a blood pressure clinic of Semnan city (in Iran) completed Medication Understanding and Use Self-Efficacy Scale were randomly selected in 2017. Data were analyzed using variance, Pearson's Correlation, and $\chi^{2}$ using the LISREL 8.8 software. Results: The items 1, 6, 7, and 8 have high correlation (at least higher than 0.60), indicating the possibility of aggregation of these four variables in the first factor (taking medication), and the four items $2,3,4$, and 5 are highly correlated with each other, which are the second factor (learning about medication). In addition, Cronbach's $\alpha$ of reliability (taking medication) for the first factor was 0.67 and 0.63 for the second factor (learning about medication) and 0.69 for the whole scale. Conclusion: The effectiveness of blood pressure self-efficacy is an appropriate tool for measure-taking responsibility for the time and taking medications by patients, and researchers can use it as a valid tool in therapeutic, psychological, and health research.
\end{abstract}

Keywords: self-efficacy, hypertension, medication use, patient comprehension, psychometrics

\section{Introduction}

Hypertension is a common chronic disorder in the metabolic system, which is recognized as an important challenge in the world's public health. It is also a polygenic and multifactorial disease, which, by disturbing metabolism, is a risk factor for abdominal obesity, dyslipidemia, and high blood sugar, known as metabolic syndrome [1]. High blood pressure is a risky factor for kidney disease, stroke, premature birth, and cardiovascular disease $[2,3]$. High blood pressure is associated with sympathetic nervous system, because increased levels of sympathetic system activity lead to high blood pressure and therapeutic treatments are effective on controlling the sympathetic nervous system and had little success in controlling and treating hypertension [4]. Researchers have found that the number of adults with high blood pressure has doubled between 1995 and 2005 [5]. According to statistics, no communicable diseases have become a major health threat in the world. It is estimated that two thirds of deaths due to cardiovascular diseases are related to high blood pressure, respiratory diseases, cancer, and diabetes [6]. Moreover, 10.4 million people die from cardiovascular disease and 28.1 million people have been announced with hypertension by the World Health Organization in 2013 [7]. Thus, $80 \%$ of people with high blood pressure are people with low and moderate income especially in developing countries [2]. Low blood pressure control is important to improve cardiovascular disease [8]. Therefore, high blood pressure control is considered as an

This is an open-access article distributed under the terms of the Creative Commons Attribution-NonCommercial 4.0 International License, which permits unrestricted use, distribution, and reproduction in any medium for non-commercial purposes, provided the original author and source are credited, a link to the CC License is provided, and changes - if any - are indicated. 
important indicator in assessing the impact of health services [2]. Studies have shown that only $50.1 \%$ of the population with high blood pressure can control their disease (with a level below 140/90 $\mathrm{mmHg}$ ) [4]. Factors, such as overweight and obesity, low exercise activities, high alcohol consumption, and the use of drugs and drugs, increase the risk of hypertension in individuals [7]. In addition, geographic location, age, gender, and other personal characteristics, such as occupation and income, education, as well as other factors, play an important role in the disease. The chance of high blood pressure is similar in population, but the distribution of the disease varies according to these risk factors in the population of patients [6]. For example, about $30 \%$ of people over the age of 18 are hypertensive, which, given the increasing prevalence of obesity, is expected to increase the number of this young population in the future, and in spite of increasing efforts to increasing awareness for controlling and treating high blood pressure is a poor diet [4]. Although blood pressure control is difficult, one can predict hypertension by examining metabolic syndrome in a person. Studies have shown that controlling high blood pressure with this method is significantly feasible and blood pressure will be decreased [1]. Blood pressure is an important risk factor for cardiovascular disease worldwide, which reduces blood pressure every $5-10 \mathrm{mmHg}, 20 \%$ of the risk of coronary artery disease, $29 \%$ of heart attacks, and $41 \%$ of stroke $[8,9]$. Although the mortality and cardiovascular morbidity rate decreases with hypertension, most of its effects remain controlled in the individual [2]. Important factors, such as receiving treatment, communicating with a doctor, adherence to treatment, and considering physical health, can play an important role in reducing and controlling blood pressure [10]. In addition, diet and lifestyle changes should be considered in the first line of treatment for patients.

Reducing salt intake of $46 \mathrm{~g}$ per day, avoiding caffeine, quitting smoking, and drinking at least $3 \mathrm{~L}$ of fluid per day should be recommended to all patients with hypertension with chronic kidney disease. The high blood pressure management reduces and cures kidney and cardiovascular diseases. It should be noted that in addition to changing lifestyle, drug treatment also plays a significant role in controlling blood pressure and reducing renal complications $[11,12]$. Psychological characteristics can also be effective in controlling the complications of the disease, one of which is psychological self-efficacy. Treatment of vascular risk factors requires a change in the behavior and adherence to treatment with long-term medication therapy, and physicians and nurses must encourage patients to adopt appropriate methods to change the factors in which the adoption of this approach entails improving self-efficacy.

Bandora believes that the person's behavior is constantly interacting with the environment and personal recognition, in which the self-efficacy is the most effective factor in the person's knowledge and refers to the person's beliefs in his ability (self-confidence) to achieve goals and proper health management in person. According to the encyclopedia of Bandora, self-efficacy beliefs determine how people feel, think, and motivate their behaviors [13]. This concept (self-efficacy) is used in two different ways in research. (1) The task of self-efficacy refers to the person's perception of his ability to perform a particular behavior. (2) Self-efficacy refers to the ability to deal with, or deal with the potential problems that a person may face in the particular person's function is busy [14]. In the results of the study, Strauss et al. [15] have shown that people with blood pressure have a high level of self-efficacy in maintaining their health and well-being. Bergstrom et al. [16], in their research, also found an important link in self-efficacy and increased physical activity and prevention in increasing waist circumference, heart rate, blood glucose and lipid levels, and control of systolic blood pressure. Gomez-Pardo et al. [17], in their research findings, have stopped smoking and tobacco as a risk factor for high blood pressure and cardiovascular risk recovery, which is also the self-efficacy of substance abuse patients. Tang et al. [2], in their study, found high self-efficacy and efficacy in controlling high blood pressure. In Iran, due to the fact that a tool for measuring and standardizing self-efficacy and it is not different domains in patients with high blood pressure. Due to the importance of self-efficacy and scientific validity of the questionnaire, standardization is not possible, and validation of this questionnaire seems necessary in Iranian society.

\section{Methods}

\section{Procedure, patients}

This was a descriptive-correlational study. The study population was 250 (89 males and 161 females) of hypertensive patients in Semnan. The mean and standard deviation of subjects' age were 51.98 and 10.41, respectively. The random sampling method was simple. The samples were taken from hospitals and specialized blood pressure clinics. The researcher visited the hospitals and clinics of Semnan Blood Pressure Center to obtain targeted information. In the case of patients who did not have the ability to read and write, the interview was completed by the researcher himself. Patients were eligible if they were 18 years of age or older, and they were excluded if they reported severely impaired vision, hearing problems, and acutely ill. A total of 270 patients were approached; 250 consented to participate in the study. Written and informed consent to participate in the study was obtained from patients. This study was performed with the obtained value of $p=0.5, d=0.05$ and with a confidence level of $90 \%$, the appropriate sample size was 270. Output of 20 samples was taken from the statistical population of high blood pressure patients. 


\section{Measures \\ Medication Understanding and Use Self-Efficacy (MUSE) Scale (Appendix)}

Self-efficacy measurement uses two subscales for understanding of and confidence in taking their prescription medications. Self-efficacy refers to the activity and practice of taking medications. In this study, we measure the effectiveness of self-efficacy to observe patients' perceptions about their ability to fight their illness. This tool consists of 18 questions with a response of two options "yes" and "no." Thus, 8 of the initial 18 items remained; four items were associated with taking medication and four items were associated with learning about medication. Cronbach's $\alpha$ has been used to assess the validity and internal validity of the project. In addition, by analyzing the Cronbach's $\alpha$ [18], in Iran, it was carried out by translating it in Persian language and a translated questionnaire was carried out on $\mathbf{3 0}$ hypertensive patients. Also, by analyzing the Cronbach's $\alpha$, Iranian credibility and narratives were also measured, which have a good validity and goodness for this tool.

\section{Analyses}

All analyses were performed using STATA version 9 (College Station, TX). Principal component analysis was used to assess the construct validity of the MUSE Scale; Cronbach's $\alpha$ was used to assess the internal consistency (reliability) of the two derived subscales. Scores on the measure could range from 0 to 32 . To examine predictive validity, a generalized linear regression model was used to determine the association between MUSE scores and patients' demonstrated understanding of prescription medication instructions, while controlling for a minimal number of covariates (age, gender, education, and literacy level). We hypothesized that higher scores on the MUSE would correspond to higher comprehension of common written prescription instructions.

\section{Results}

Before analyzing the data, the overall status of the data was examined. At first, the existence of data outside the scope was investigated. Subsequently, unreported data were examined to determine that no unreported data exists. In addition, single-variable perforation data were analyzed using Box Plot and the results showed that there are 27 univariate data that were removed from a total of 250 data, and the Mahalanobis statistic also showed that the data have no multiple variables. Also, the values of skidding and elongation of the autoimmune of selfefficacy treatment variable were investigated, the result showed that the values of the case were not exceeded by the critical limit of \pm 1 (kurtosis $<1$ and skewness $<1$ ).
In addition, the independence of errors in variable structure of blood pressure self-efficacy was investigated by Durbin-Watson Camera (DW) statistics and showed that the error values in the variable structures are independent $(\mathrm{DW}<2)$. Also, multiple synchronizations were evaluated by tolerance and [variance inflation factor (VIF)] statistics and the results showed that there were no multiple synchronizations and none of the tolerance values were less than 0.1 , and none of the values (VIF) were greater than the permitted limit of 10 .

\section{Exploratory factor analysis}

First, an exploratory factor analysis was used to analyze the factors and psychometric properties of the blood pressure self-efficacy questionnaire. Then, a confirmatory factor analysis was presented.

Kaiser-Meyer-Olkin and Bartlett's test for sample size sufficiency and reducing hidden variables show that the sampling volume is suitable for performing factor analysis, suggesting that the variance of the variables under consideration is affected by the hidden factor, meaning that there is a significant relationship between the variables, therefore, the desired analysis is safe $(p<0.01)$.

Table I shows the factor of eight questions of this scale to be able to explain their acceptable variance by the agent. The findings of the table indicate that the acceptable variance of scale questions is explained by the desired factors. And only question 5 is less than optimal.

Table II shows the value of the variance explained by the extracted factors with special values. The results of the above table indicate that out of a total of eight possible variables, the two factors with extraction values are 29.81 and 0.23 for the variables desired (after rotation) and with a special value greater than 1 , and these two factors explain 52.82 out of the variance of the scale variables.

Figure 1 indicates a large primary factor (hypertension autoimmunity) with a special value greater than 2.5 and the other two acceptable factors with a value greater than

Table I Evaluating the contribution factor of 18 questions of this scale to be able to explain their acceptable variance by the agent

\begin{tabular}{llc} 
Items & $N$ & Extracted amount \\
1 & 1 & 0.400 \\
3 & 1 & 0.758 \\
5 & 1 & 0.818 \\
6 & 1 & 0.418 \\
7 & 1 & 0.300 \\
9 & 1 & 0.470 \\
10 & 1 & 0.541 \\
12 & 1 & 0.531 \\
\hline
\end{tabular}


Majdabadi et al.

Table II Value of the variance explained by the extracted factors with special values

\begin{tabular}{|c|c|c|c|c|c|c|c|c|c|}
\hline \multirow[b]{2}{*}{ Factors } & \multicolumn{3}{|c|}{ Special initial values } & \multicolumn{3}{|c|}{ Total squared load factor } & \multicolumn{3}{|c|}{ Total sum of squares } \\
\hline & Total & Variance & Cumulative & Total & Variance & Cumulative & Total & Variance & Cumulative \\
\hline 1 & 2.64 & 33.09 & 33.09 & 2.64 & 33.09 & 2.64 & 2.38 & 29.81 & 29.81 \\
\hline 2 & 1.57 & 19.73 & 52.82 & 1.57 & 19.73 & 1.57 & 1.84 & 23.00 & 52.82 \\
\hline 3 & 0.961 & 12.00 & 64.83 & & & & & & \\
\hline 4 & 0.799 & 9.98 & 74.81 & & & & & & \\
\hline 5 & 0.649 & 8.11 & 82.92 & & & & & & \\
\hline 6 & 0.578 & 7.22 & 90.15 & & & & & & \\
\hline 7 & 0.496 & 6.20 & 96.35 & & & & & & \\
\hline 8 & 0.291 & 0.361 & 100.00 & & & & & & \\
\hline
\end{tabular}

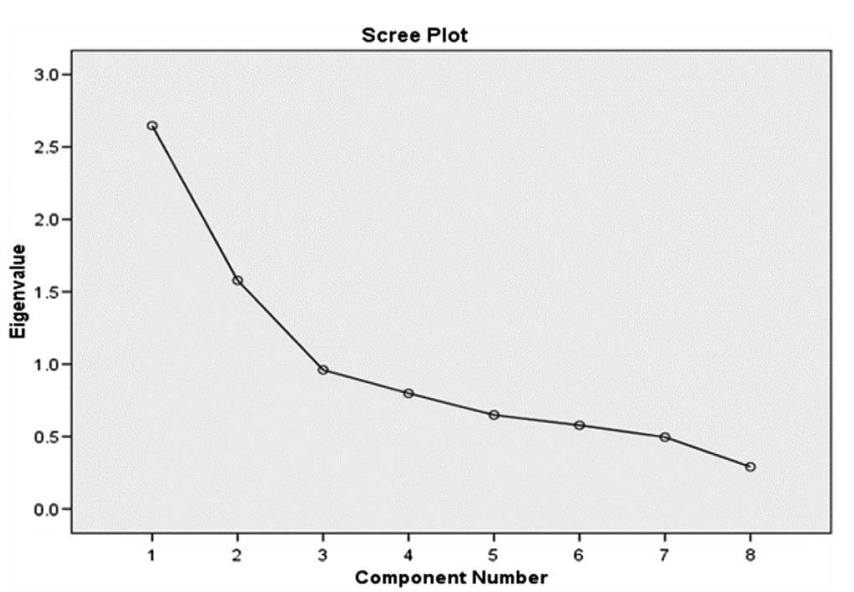

Fig. 1. The scree chart for special value items

$\mathrm{l}$ (taking medication and learning). Drug intake can be extracted on the investigated scale.

Table III shows the correlated matrices between the items with the extracted factors. The findings of this table show that the items $1,6,7$, and 8 have a good and high correlation (at least higher than 0.60), indicating the possibility of aggregation of these four variables in the

Table III The correlated matrices between the items with the extracted factors

\begin{tabular}{lcc} 
Items & Factor 1 & Factors \\
1 & 0.616 & Factor 2 \\
2 & 0.041 & 0.133 \\
3 & 0.055 & 0.870 \\
4 & 0.546 & 0.903 \\
5 & 0.451 & 0.347 \\
6 & 0.682 & 0.304 \\
7 & 0.723 & -0.052 \\
8 & 0.716 & 0.135 \\
\hline
\end{tabular}

first factor (taking medication), and the four items 2, 3, 4, and $\mathbf{5}$ are also highly correlated with each other and have very low correlation with the other four, which are the second factor (learning about medication). It is worth noting that in the first factor, two questions 4 and 5 have a high correlation with the first factor, but when they are in the second factor, their correlation with the quadruple of the first factor drops significantly, so these two terms must be in the second place of the factor. In addition, the Cronbach's $\alpha$ of reliability for the first factor (taking medication) was 0.67 and 0.63 for the second factor (learning about medication), and 0.69 for the whole scale.

\section{Confirmation factor analysis}

In the following, the results of the confirmatory factor analysis using the LISREL 8.8 software have been reviewed and presented to review the relationship between variables in a dominant two-factor model.

Factor load factors of the questionnaires show the selfefficacy of hypertension on the two factors of this questionnaire (Table $I V)$. The findings of this table show that each of the eight questions of this questionnaire is significantly loaded on its agent $(T>2)$. The standard values of these loads, along with the diagrammatic representation of the factor analysis, are presented below.

Figure 2 shows the standard factor load of the scale questions of the factors related to it. In addition to indicating each question for the relevant agent, this figure shows that the most effective markers in the factor of drug use are the questions 7 (factor load 0.84), 6 and 8 equally (with factor load 0.77), and the 1 (factor load 0.68). And in the drug-learning agent, questions 3 (with a factor of $0.95), 2$ (with a factor of 0.86 ), 4 (with a yield of 0.41 ), and 5 (with a gain of 0.34 ) are in the order of the fastest to the weakest markers for your agent.

For the general model, the structural equation has several fitting indexes, each of which in the particular case 
Table IV Factor load factors of the questionnaires show the selfefficacy of hypertension on the two factors of this questionnaire (MUSE)

\begin{tabular}{|c|c|c|c|c|}
\hline \multirow[b]{2}{*}{ Parameters } & \multicolumn{2}{|c|}{$\begin{array}{c}\text { The items of } \\
\text { taking } \\
\text { meditation }\end{array}$} & \multicolumn{2}{|c|}{$\begin{array}{c}\text { The items of } \\
\text { learning } \\
\text { about } \\
\text { medication }\end{array}$} \\
\hline & & $\mathrm{N}$ & & $\mathrm{N}$ \\
\hline Factor structural & Q2 & 0.899 & Q1 & 0.714 \\
\hline $\begin{array}{l}\text { Standard error of the } \\
\text { estimate }\end{array}$ & & 0.065 & & 0.066 \\
\hline$t$ & & 13.82 & & 78.10 \\
\hline Factor structural & Q3 & 0.997 & Q6 & 0.803 \\
\hline $\begin{array}{l}\text { Standard error of the } \\
\text { estimate }\end{array}$ & & 0.064 & & 0.064 \\
\hline$t$ & & 15.66 & & 12.62 \\
\hline Factor structural & Q4 & 0.443 & Q7 & 0.880 \\
\hline $\begin{array}{l}\text { Standard error of the } \\
\text { estimate }\end{array}$ & & 0.070 & & 0.062 \\
\hline$t$ & & 6.16 & & 12.29 \\
\hline Factor structural & Q5 & 0.355 & Q8 & 0.803 \\
\hline $\begin{array}{l}\text { Standard error of the } \\
\text { estimate }\end{array}$ & & 0.071 & & 0.046 \\
\hline$t$ & & 4.98 & & 12.61 \\
\hline
\end{tabular}

MUSE: Medication Understanding and Use Self-Efficacy shows the highest accuracy or weakness; therefore, the presentation of several fit indexes for each general model of equations is important. In this model, some indicators also indicate that the model was fitted and some of the indicators were in violation. The first is the $\chi^{2}$ gradient. $\chi^{2}$ was obtained for the fitting of the model with a grade of $19\left(\chi^{2}=56.86\right)$, which is significant at $\alpha$ level less than 0.01 . The roots of the variance of the approximation error were also significant (root mean square error of approximation $<0.05$ ). But the softened fitness index is higher than 0.95 , which is the preferred mode for fitting the model, does not show model fitness (normed fit index $=$ $0.205)$. In addition, the softness index is also a fitness indicator (non-normed fit index $=-0.175$ ). Also, the comparative fit index showed that the model was not fit for comparison with the base line model (confirmatory fit index $=0.203$ ). Also, the goodness of fit index was less than the significance level of 0.95 (goodness of fit index $=0.689$ ), which was indicative of fit data - the model is not. But the succinct fit index and the cohesive criterion index are, respectively, (adjusted goodness of fit index $=-0.411$ ) and (parsimony goodness of fit index $=$ 0.364 ), which indicate other fitness indicators by adjusting for physical fitness (parameter fixing).

And a decrease in the degree of freedom did not suffer a lot, so the model is appropriate in terms of the right principle and the relevance of the model piece of information.

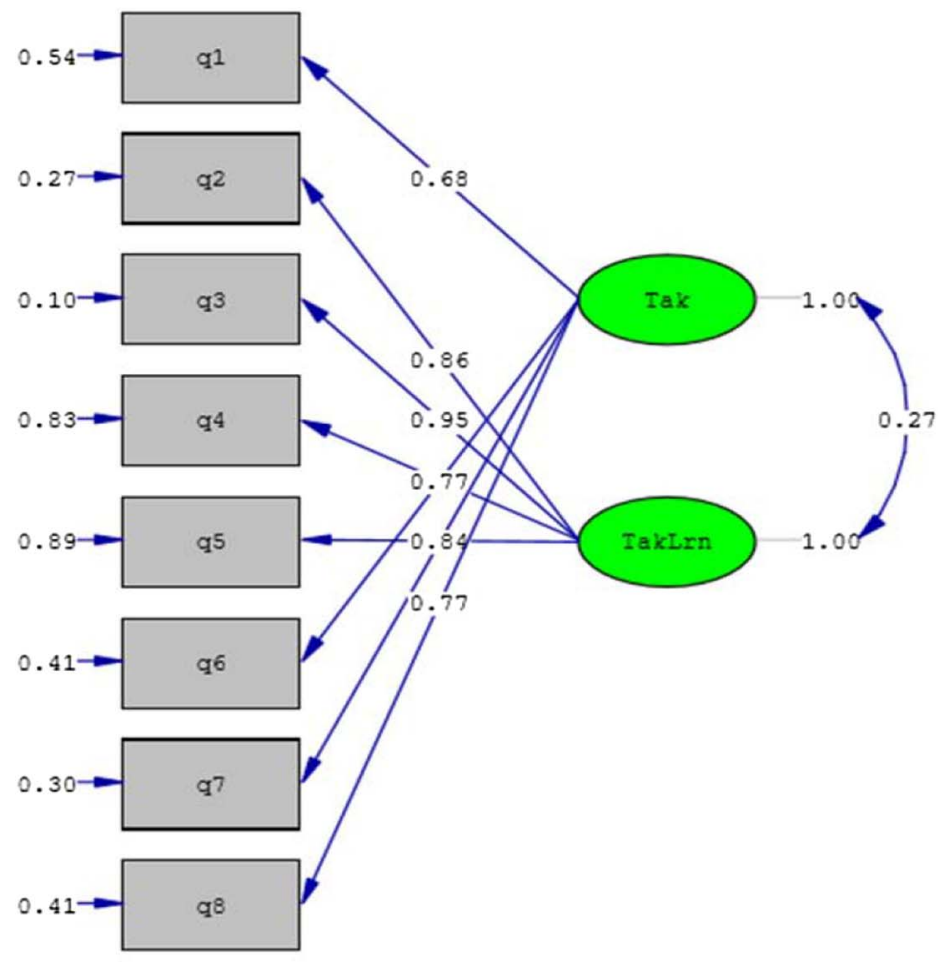

Chi-Square=400.10, df=19, P-value=0.00000, RMSEA=0.301

Fig. 2. Standard factor load of the scale questions 
To assess the validity of the self-efficacy of blood pressure, this scale was performed with adherence to treatment questionnaire, simultaneously, on the sample group. The data were analyzed using Pearson's correlation coefficient.

Table $V$ shows the correlation between hypertension autoimmunity and its factors with the adherence to treatment variable. The findings of this table indicate that the self-efficacy variable of treatment (with its two factors) with the adherence to treatment variable of treatment as a similar tool has a significant correlation, and according to the photo scoring of the adherence to the treatment with the autoimmune blood pressure, correlations are negative.

In this study, the findings from an obtained sample can be generalized to the research community, and the results of the research can be generalized to similar situations, and, in this study, the extent of the contribution of the independent variable to the dependent variable was studied. In this case, the research has an external validity.

\section{Discussion}

Treatment of vascular risk factors requires a change in the behavior and compliance of long-term medication therapy. Health literacy and self-efficacy are widely predictive of a person's ability to adherence to treatment and to adhere to specific dietary regimens. Studies have shown that patients with vascular diseases and blood pressure and likely have limited health literacy and are more likely to misunderstand or misinterpret the use of medication guidelines [19-22]. Therefore, this study aimed to validate the autoimmunity of the MUSE Blood pressure Questionnaire on a 250-person sample of this disease in Semnan city hospitals. The findings of this study indicated that the self-efficacy questionnaire of hypertension was saturated with two factors. These three factors are based on theoretical basis of research and the content of questions on factors and in accordance with previous

Table V Correlation of hypertension autoimmunity and its factors with the adherence to treatment variable

\begin{tabular}{lccc} 
Variables & $\begin{array}{c}\text { Taking } \\
\text { meditation }\end{array}$ & $\begin{array}{c}\text { Learning } \\
\text { about } \\
\text { medication }\end{array}$ & $\begin{array}{c}\text { Adherence } \\
\text { to treatment }\end{array}$ \\
$\begin{array}{l}\text { MUSE } \\
\text { Taking }\end{array}$ & 1 & & \\
$\begin{array}{l}\text { meditation } \\
\begin{array}{l}\text { Learning about } \\
\text { medication }\end{array}\end{array}$ & $0.728^{* *}$ & 1 & \\
$\begin{array}{l}\text { Adherence to } \\
\text { treatment }\end{array}$ & $-0.334^{* *}$ & $-0.465^{* *}$ & $-0.158^{*}$ \\
\hline
\end{tabular}

MUSE: Medication Understanding and Use Self-Efficacy.

**Correlation is significant at the 0.01 level.

*Correlation is significant at the 0.05 level researches, such as the main makers of the tool [18], which considered two factors for the self-efficacy questionnaire of hypertension, the factor of using prescription medication, and learning prescription medication. The results of confirmatory factor analysis showed that all of the coefficients of the raw and standard paths were significant, as well as some indicators of goodness of fit showed the fitness of the data with the model. Therefore, the two-factor structure of the blood pressure questionnaire was confirmed. In general, self-efficacy is interpreted in two ways: first, the task of self-efficacy is one's perception of one's ability to perform a particular behavior and second as the ability of the individual to deal with and control, or to cope with potential problems in the homework and the particular function that individual it points to the fact that [23]. Using prescription medication agent also directly refers to the patient's responsibility for taking medications, also learning how to use prescription medications is related to knowledge and information, instructions, and the time of medications [18]. The Cronbach's $\alpha$ coefficient was used to determine the reliability of the MUSE Blood Pressure Questionnaire. The findings of this study showed that the reliability of the blood pressure Self-Efficacy Questionnaire was acceptable. Also, the reliability of each subscale of the questionnaire was high, which indicates the high reliability of the tool. These findings were in line with the findings of Cameron et al. [18] and Wolf et al. [24]. To calculate the validity of the instrument, this scale was implemented with the scale of adherence to treatment, and the result of the simultaneous validity of the instrument was adherence to treatment. Restrepo et al. [25], in his study on adherence to treatment, has defined the level of compliance of the individual with health recommendations and drug therapies. Adherence to treatments includes diet therapy, dietary recommendations, physical activity, dietary regimen, and so on [26]. According to this description, it seems logical that people who have a blood pressure selfefficacy, which means that they have the responsibility to take medication, as well as the timing and administration of the drug, are also in some ways compliant with the treatment. The relationship between blood pressure and treatment was significant, and according to the negative design of the scale of treatment compliance, this relationship was negatively represented. Regardless of the conditions and facilities that have been implemented in it, there are usually some limitations that can reduce the scope of its decision-making to the entire community, including the limitations of this study. The lack of a single and specific clinic for patients with hypertension has been found in Semnan city. Another limitation is the selection of patients from Semnan city who may differ in terms of facilities, situations, and problems in comparison with patients living in smaller cities or villages. It is recommended to reinvent the questionnaire from number of samples and larger statistical community. 


\section{Conclusions}

According to the results, it seems that considering the ease of implementation, ease of scoring, ease of interpretation, the ability to be implemented individually and in group, the feasibility, validity, and reliability, the effectiveness of blood pressure self-efficacy is an appropriate tool for sizetaking responsibility for the time and taking medications by patients, and researchers can use it as a valid tool in therapeutic, psychological, and health research.

$$
* * *
$$

Funding sources: None.

Authors' contribution: RG wrote the manuscript. RG, MA, and HAM collected the data of the manuscript. RG and HAM contributed in data analysis. They also designed the study, supervised the group, and revised the manuscript prior to submission.

Conflict of interest: The authors declare no conflict of interest in relation to the work.

\section{References}

1. Xiao J, Hua T, Shen H, Zhang M, Wang XJ, Gao YX, Lu Q, Wu C: Associations of metabolic disorder factors with the risk of uncontrolled hypertension: A follow-up cohort in rural China. Sci Rep 7, 743 (2017)

2. Tang S, Bishwajit G, Ji L, Feng D, Fang H, Fu H, Shao T, Shao P, Liu C, Feng Z, Luba TR: Improving the blood pressure control with the proactive attitude of hypertensive patients seeking followup services: Evidence from China. Medicine 95, e3233 (2016)

3. Hosseininasab M, Jahangard-Rafsanjani Z, Mohagheghi A, Sarayani A, Rashidian A, Javadi M, Ahmadvand A, Hadjibabaie M, Gholami K: Self-monitoring of blood pressure for improving adherence to antihypertensive medicines and blood pressure control: A randomized controlled trial. Am J Hypertens 27, 1339-1345 (2014)

4. Bhatt N, Long SA, Gardner EA, Tay J, Ladich E, Chamberlain D, Fogarty TJ, Maguire PJ: Radiosurgical ablation of the renal nerve in a porcine model: A minimally invasive therapeutic approach to treat refractory hypertension. Cureus 9, e1055 (2017)

5. Gu H, Ma Z, Wang J, Zhu T, Du N, Shatara A, Yi X, Kowala MC, Du Y: Salt-dependent blood pressure in human aldosterone synthase-transgenic mice. Sci Rep 7, 492 (2017)

6. Wang J, Ma JJ, Liu J, Zeng DD, Song C, Cao Z: Prevalence and risk factors of comorbidities among hypertensive patients in China. Int J Med Sci 14, 201-212 (2017)

7. Aune D, Sen A, Vatten LJ: Hypertension and the risk of endometrial cancer: A systematic review and meta-analysis of case-control and cohort studies. Sci Rep 7, 44808 (2017)

8. Lee CJ, Park S: The role of home blood pressure telemonitoring for blood pressure control. Pulse (Basel, Switzerland) 4, 78-84 (2016)

9. Ding M, Huang T, Bergholdt HK, Nordestgaard BG, Ellervik C, Qi L: Dairy consumption, systolic blood pressure, and risk of hypertension: Mendelian randomization study. BMJ 356, j1000 (2017)

10. Franssen M, Farmer A, Grant S, Greenfield S, Heneghan C, Hobbs R, Hodgkinson J, Jowett S, Mant J, Martin U, Milner S, Monahan M, Ogburn E, Perera-Salazar R, Schwartz C, Yu LM, McManus RJ: Telemonitoring and/or self-monitoring of blood pressure in hypertension (TASMINH4): Protocol for a randomised controlled trial. BMC Cardiovasc Disorders 17, 58 (2017)
11. Novello MF, Rosa ML, Ferreira RT, Nunes IG, Jorge AJ, Correia DM, Martins WA, Mesquita ET: Compliance with the prescription of antihypertensive medications and blood pressure control in primary care. Arq Bras Cardiol 108, 135-142 (2017)

12. Helal I, Al-Rowaie F, Abderrahim E, Kheder A: Update on pathogenesis, management, and treatment of hypertension in autosomal dominant polycystic kidney disease. Saudi J Kidney Dis Transpl 28, 253-260 (2017)

13. Tsang SK, Hui EK, Law BC: Self-efficacy as a positive youth development construct: A conceptual review. Sci World J 2012, 452327 (2012)

14. Khalili F, Eslami AA, Farajzadegan Z, Hassanzadeh A: The association between social-psychological factors and treatment adherence behaviors among maintenance hemodialysis patients in Isfahan, Iran: A conceptual framework based on social cognitive theory. Health Syst Res 3, 278-290 (2011)

15. Strauss SM, Jensen AE, Bennett K, Skursky N, Sherman SE, Schwartz MD: Clinicians' panel management self-efficacy to support their patients' smoking cessation and hypertension control needs. Transl Behav Med 5, 68-76 (2015)

16. Bergstrom G, Borjesson M, Schmidt C: Self-efficacy regarding physical activity is superior to self-assessed activity level, in longterm prediction of cardiovascular events in middle-aged men. BMC Public Health 15, 820 (2015)

17. Gomez-Pardo E, Fernandez-Alvira JM, Vilanova M, Haro D, Martinez R, Carvajal I, Carral V, Rodríguez C, de Miguel M, Bodega P, Santos-Beneit G, Peñalvo JL, Marina I, Pérez-Farinós N, Dal Re M, Villar C, Robledo T, Vedanthan R, Bansilal S, Fuster V: A comprehensive lifestyle peer group-based intervention on cardiovascular risk factors: The randomized controlled fifty-fifty program. J Am College Cardiol 67, 476-485 (2016)

18. Cameron KA, Ross EL, Clayman ML, Bergeron AR, Federman AD, Bailey SC, Davis TC, Wolf MS: Measuring patients' selfefficacy in understanding and using prescription medication. Patient Educ Couns 80, 372-376 (2010)

19. Davis TC, Wolf MS, Bass PF 3rd, Thompson JA, Tilson HH, Neuberger M, Parker RM: Literacy and misunderstanding prescription drug labels. Ann Intern Med 145, 887-894 (2006)

20. Persell SD, Osborn CY, Richard R, Skripkauskas S, Wolf MS: Limited health literacy is a barrier to medication reconciliation in ambulatory care. J Gen Intern Med 22, 1523-1526 (2007)

21. Wolf MS, Davis TC, Arozullah A, Penn R, Arnold C, Sugar M, Bennett CL: Relation between literacy and HIV treatment knowledge among patients on HAART regimens. AIDS Care 17, 863873 (2005)

22. Wolf MS, Davis TC, Shrank W, Rapp DN, Bass PF, Connor UM, Clayman M, Parker RM: To err is human: Patient misinterpretations of prescription drug label instructions. Patient Educ Couns 67, 293-300 (2007)

23. Lorig K, Chastain RL, Ung E, Shoor S, Holman HR: Development and evaluation of a scale to measure perceived self-efficacy in people with arthritis. Arthritis Rheum 32, 37-44 (1989)

24. Wolf MS, Chang CH, Davis T, Makoul G: Development and validation of the Communication and Attitudinal Self-Efficacy Scale for cancer (CASE-cancer). Patient Educ Couns 57, 333-341 (2005)

25. Restrepo RD, Alvarez MT, Wittnebel LD, Sorenson H, Wettstein R, Vines DL, Sikkema-Ortiz J, Gardner DD, Wilkins RL: Medication adherence issues in patients treated for COPD. Int J Chron Obstruct Pulmon Dis 3, 371-384 (2008)

26. Gonzalez JS, McCarl LA, Wexler DD, Cagliero E, Delahanty L, Soper TD, Goldman V, Knauz R, Safren SA: Cognitive behavioral therapy for adherence and depression (CBT-AD) in type 2 diabetes. J Cognit Psychother 24, 329-343 (2010) 


\section{Majdabadi et al.}

\section{Appendix: Original MUSE Scale items}

\section{Original scale items}

1. It is easy for me to take my medicine on time.

2. It is easy for me to ask my doctor questions about my medicine.

3. It is easy for me to ask my pharmacist questions about my medicine.

4. It is easy for me to understand my doctor's instructions for my medicine.

5. It is easy for me to understand my pharmacist's instructions for my medicine.

6. It is easy for me to understand instructions on medicine bottles.

7. It is easy for me to get all the information I need about my medicine.

8. My medicines are easy to take.

9. It is easy to remember to take all my medicines.

10. It is easy for me to set a schedule to take my medicines each day.

11. It is easy for me to learn how to take my medicines.

12. It is easy for me to take my medicines every day.

13. If I miss a dose of my medicine, it is easy for me to know what to do.

14. I am confident that I am able to deal with any unexpected health problems.

15. If I don't understand something, it is easy for me to ask for help.

16. I know that I will be able to actively participate in decisions about my health.

17. It is easy for me to take my medicines the way I am supposed to.

18. Taking my medicines is part of my daily routine.

Items in plain text were eliminated in the first principal components factor analysis due to low factor loadings. The single item in italics was eliminated upon a second principal components factor analysis due to low factor loadings on both factors $(<0.30$ on both factors $)$. Bolded items are retained in final MUSE Scale 